\title{
Predictions on availability and possibilities of the use of wood for energy purposes in Europe and in Poland
}

\author{
Adam Kaliszewski $\bowtie$, Piotr Gołos \\ Forest Research Institute, Department of Forest Management, Sękocin Stary, Braci Leśnej 3, 05-090 Raszyn, Poland, \\ phone +48 22 7150678, fax: +48 22 7153837, e-mail: A.Kaliszewski@ibles.waw.pl
}

\begin{abstract}
The paper presents the results of studies concerning the availability and possibilities of the use of wood for energy purposes in Europe and in Poland. It describes in detail the current use of wood for energy production purposes, as well as predictions on volume, composition, and sources of energy wood. It also presents the results concerning potential impact of energy wood harvesting on wood industries. The paper concludes that the question of utilization of forest biomass for large-scale energy generation is very complex and has far-reaching consequences for environment, society and economy. So as to be effective, wood resources management should give a priority to wood-based production of the greatest added value, and energy generation should be a closing-down stage in the wood value chain.
\end{abstract}

\section{KEY WORDS}

climate policy, energy wood, wood-based sector

\section{INTRODUCTION}

In March 2007, the European Council unanimously adopted so-called 20-20-20 targets, i.e. general targets of the EU energy and climate policy. In particular, for the whole EU they include:

- reducing greenhouse gas emissions by $20 \%$ (with a commitment to move to $30 \%$, within the framework of an ambitious and comprehensive global agreement);

- increasing to $20 \%$ a share of renewable energy sources in the total energy consumption within the EU;

- improving of energy efficiency by $20 \%$ (Communication 2010).
The development of renewable energy sources is at the EU-level substantially supported by the Directive 2009/28/EC of the European Parliament and of the Council of 23 April 2009 on the promotion of the use of energy from renewable sources, which amends and subsequently repeals Directives 2001/77/EC and 2003/30/EC. According to this directive Poland is obliged to attain at least $15 \%$ share of energy from renewable sources in gross final consumption of energy by 2020. Moreover, each Member State is obliged to assure that their shares of renewables in all means of transport will amount to at least $10 \%$ of the final energy consumption by 2020 (Directive 2009/28/EC).

The document encourages Member States to promote greater mobilisation of existing timber reserves and development of new forestry systems in order to exploit 
the full potential of biomass (Preamble, 24). Simultaneously, the use of forest biomass for fulfilling a Member State's renewable energy obligations requires that the sustainability criteria for biofuels and bioliquids, stated in the Article 17 par. 2-6 of the Directive, are met. They shall not be, inter alia, made from raw material obtained from land with high biodiversity value, as well as from wetlands and continuously forested areas.

The Directive 2009/28/EC still needs transposition to the Polish law. According to the Article 27 thereof, Member States shall bring into force the laws, regulations and administrative provisions necessary to comply with this Directive by 5 December 2010 (Directive 2009/28/EC).

As of January 2014, the bill of the Act on Renewable Energy Sources, aiming at completing the transposition of the Directive 2009/28/EC to the Polish legislation, is still being developed by the Council of the Ministers (Government Legislation Centre 2014).

The aim of this paper is to present the results of the most significant studies concerning the availability and possibilities of the use of wood for energy purposes in Europe and in Poland. It needs to be noticed that literature on this topic is rather modest, and the conducted studies are mostly general estimations. The paper also describes the most important expected consequences of using wood as fuel for the whole timber sector.

\section{Current use of woOd for energy PRODUCTION PURPOSES IN THE EUROPEAN Union AND IN Poland}

According to the Eurostat, within the EU, just over two fifths of the land area is classified as wooded land ("forests" or "other wooded land"), which is a similar proportion to that used for agricultural purposes and amounts to 177.8 million hectares (2010). The total fellings of wood in all EU-countries in 2009 amounted to 484 million $\mathrm{m}^{3}$ over bark. $42 \%$ of this volume (i.e. some 203 million $\mathrm{m}^{3}$ ), including 47.5 million $\mathrm{m}^{3}$ of chips and particles and 38.8 million $\mathrm{m}^{3}$ of wood residues and pellets, were allocated on energy purposes (Eurostat 2011). The intake of wood biomass consumption for energy production increases by around $20 \%$ every year. It is mostly caused by subsidies for using wood in energy generating processes. In the future, the growth dynam- ics is predicted to be even higher, which already now causes essential problems for other sectors of woodbased industry (Bernasiński 2011).

The general assessment of raw wood utilization in the European Union was presented by Mantau (2010). According to his results, in 2010 some 804 million $\mathrm{m}^{3}$ of wood biomass was used, 346 million $\mathrm{m}^{3}$ of which was assigned for energy production. Households contributed to the largest extent to the overall consumption of wood for energy purposes (45\%). The share of forestbased industries (for their own use) and biomass electric plants amounted to $25 \%$ and $24 \%$, respectively.

In Poland, according to the Central Statistical Office (GUS), fuel wood harvesting in 2010 amounted to over 4.1 million $\mathrm{m}^{3}$ which was $21 \%$ more as compared to $2005\left(3.4\right.$ million $\left.\mathrm{m}^{3}\right)$. The figures represent only the volume of wood classified as "fuel wood" and correspond to the volume of S4 (large firewood) and $\mathrm{M}_{2}$ (small firewood) grades (GUS 2011). Additionally, in 2010 the volume of S2AC (fuel pile wood) and S2AP (pile wood for general purposes) grades, as well as wood chips and pellets, amounted to 534.2, 143.3, and 84.7 thousand $\mathrm{m}^{3}$, respectively (Ballaun 2013).

According to Ratajczak et al. (2011) there is no comprehensive information about potential for forest biomass utilization in Poland. The authors claim that according to different sources the volume of wood derived from forests in Poland may amount to $4.0-8.2$ million $\mathrm{m}^{3}$. The studies conducted at the Wood Technology Institute in Poznań indicate that in 2009 the potential theoretical supply of timber by-products (so called "waste industrial timber") available for energy purposes amounted to 5.1 million $\mathrm{m}^{3}$, which was $50 \%$ of their total supply, and potential supply of recovered industrial wood totalled to 6.0 million $\mathrm{m}^{3}, 88 \%$ of which was solid wood. In addition, wood originating from fast-growing forest plantations should also be classified as wood biomass resources available for energy production. They altogether cover an area of 10 thousand hectares and produce around 200 thousand $\mathrm{m}^{3}$ of wood biomass annually. The authors conclude that estimated technical capacity of wood biomass available for energy purposes in Poland in 2009 totalled to around 15 million $\mathrm{m}^{3}$. Wood biomass available from forestry comprises $41 \%$ of this volume, while wood biomass from timber sector constitutes $34 \%$. Twenty three percent of that wood comes from public utilities and $2 \%$ from agriculture. 


\section{Predictions on volume, composition, AND SOURCES OF ENERGY WOOD IN EUROPE}

The comprehensive, multi-scenario projections on volume and sources of wood for energy purposes in Europe (excluding Russian Federation) have been presented in "The European Forest Sector Outlook Study II. 2010-2030" (UNECE 2011). The report presents results of analyses conducted using a number of mathematical models. It needs, however, to be stressed that presented estimations of demand for energy wood are based on insufficient data, which makes the forecasts being highly uncertain. Two scenarios included in the report are discussed below:

- Reference scenario or so-called baseline or business-as-usual scenario, that provides a picture of a future without major changes from the past, i.e. current policies remain unchanged, and current trends continue;

- Promoting wood energy scenario, which explores how the forest sector could contribute to meeting the renewable energy targets and what would be the consequences for this sector.

According to the Reference scenario, based on the increase in Gross Domestic Product, the total consumption of wood products in Europe is projected to rise from 739 million $\mathrm{m}^{3}$ roundwood equivalent (RWE) in 2010 to 853 million $\mathrm{m}^{3}$ in 2030. In the same period, wood demand for energy use is predicted to increase from 434 million $\mathrm{m}^{3}$ RWE in 2010 to 585 million $\mathrm{m}^{3}$ RWE in 2030. In order to fulfil the increasing demand for wood products and energy, removals should rise by $15 \%$ in 2030 as compared to 2010 , i.e. to 685 million $\mathrm{m}^{3}$ over bark of stemwood, which is still well below the potential sustainable supply estimated at around 750 million $\mathrm{m}^{3}$ over bark of stemwood annually.

For the Reference scenario it is assumed that all countries would implement harvest residue extraction, based on the current practice and guidelines of the most advanced countries. Annual harvest residue extraction would increase by $278 \%$ from 32.8 million $\mathrm{m}^{3} \mathrm{RWE}$ in 2010 to 91.4 million $\mathrm{m}^{3}$ RWE in 2030. In 2010 harvest residues were equivalent to $2.5 \%$ of stemwood removals, but they are projected to rise up to $6 \%$ by 2030 . This means a significant increase in the intensity of harvesting methods over the two decades. The total potential is estimated to be 117 million $\mathrm{m}^{3}$ RWE per year, and the important share of it is assumed to be from extracted stumps (their annual volume is projected to increase from 3.6 million $\mathrm{m}^{3}$ to 12.1 million $\mathrm{m}^{3} \mathrm{RWE}$ ).

In the Promoting wood energy scenario, a priority is given to the official targets for renewable energy. In accordance with this assumption, the use of wood for energy in 2030 would be nearly 860 million $\mathrm{m}^{3}, 60 \%$ of total wood consumption, while in the Reference scenario it amounted to $50 \%$. The total wood supply is projected to reach over 1.4 billion $\mathrm{m}^{3}$ in 2030, 250 million $\mathrm{m}^{3}(22 \%)$ more than in the Reference scenario. The total supply of wood for energy is assumed to increase by 270 million $\mathrm{m}^{3}$ in 2030 as compared to the Reference scenario and by 424 million $\mathrm{m}^{3}$ in comparison to 2010 . This would be a rise of $98 \%$ in 20 years.

The Promoting wood energy scenario indicates that it may be technically possible for wood from existing European forests and the downstream wood flows to supply $40 \%$ of the renewable energy targets, provided that energy efficiency improves significantly compared to 2010 and that renewable energies other than wood expand considerably faster than wood energy. It seems to be technically possible to supply 1.4 billion $\mathrm{m}^{3}$ annually of wood in 2030. It would, however, require intensification of silviculture and harvesting operations and significant increase in extraction of harvest residues and stumps (272 million $\mathrm{m}^{3}$ in 2030, compared to 36 million $\mathrm{m}^{3}$ in 2010, stemwood removals would rise to 114 million $\mathrm{m}^{3}$ and would be 30 times larger than in 2010), and landscape care wood (increase by 27 million $\mathrm{m}^{3}$ ).

In addition, it is projected that in the Promoting wood energy scenario 30 million $\mathrm{m}^{3}$ of wood annually would need to be imported from other regions. If it proved impossible to mobilise these volumes of harvest residues and stumps, meeting the targets would require a further increase of volumes of imported wood, as well as extension of fast growing plantations on non-forest land, or faster expansion of non-wood renewable energies (which are already assumed to grow faster than wood).

Energy wood mobilization projected in the Promoting wood energy scenario would have unfavorable effects on the whole wood industry. The supply of wood for that industry would decrease by some 20 million $\mathrm{m}^{3}$, while wood prices would increase.

It should be noticed, that Promoting wood energy scenario would result in very high financial, social, 
and environmental costs. Forest biomass mobilization would negatively affect forest ecosystems, as well as impair tourist and recreational conditions in forests (UNECE 2011).

\section{Predictions for use energy wood in Poland}

Objectives for use of renewable energy sources have been defined in the "Energy Policy of Poland until 2030" (Energy Policy 2009). They include:

- Increasing the use of renewable energy sources in the final energy use to at least $15 \%$ in 2020 and further increase in the following years,

- Increasing the share of biofuels in the market of transport fuels to $10 \%$ by 2020 , and increasing the use of second generation biofuels,

- Protecting forests against overexploitation in order to obtain biomass, and balanced use of agricultural areas for production of renewable energy sources, including biofuels, so as not to allow competition between renewable energy production and agriculture and to preserve biodiversity;

- Using the existing weirs owned by the State Treasury for power generation;

- Increasing the diversification of supply sources and the creation of optimal conditions for distributed power generation based on locally available resources.

With regards to Poland, predictions for volume and sources of energy wood until 2020 have been included in the "National Renewable Energy Action Plan", adopted by the Council of Ministers in December 2010 (National Renewable... 2010). It places emphasis on development of non-forest renewable energy sources and use of waste, indicating the possibilities of increased supply of forest energy biomass in improving stumps extraction and other by-products harvesting technologies and expanding the country's forest cover, but not in intensifying forest harvesting.

Implementation of these assumptions has been fostered by policy instruments enforcing the use of nonforest biomass in biomass co-firing technologies. According to two executive acts to the Energy Law of 10 April 1997 (Regulation 2008, 2010) use of wood biomass originating from forest residues and waste, as well as from forest-based industries, in power plants and heat power stations generating more than $5 \mathrm{MW}$ has been excluded from the Green Certificate System (those plants and stations are not allowed to receive green certificates). In 2010 the minimal share of non-forest biomass amounted to $25 \%$ (before 2010 it amounted to $20 \%$ ), and in each subsequent year it is to increase by 15\%. From 2015 onwards, it will not be allowed to use forest biomass within the Green Certificate System in Poland. This regulation intends to use to a greater extent biomass originating from agricultural energy plantations in co-firing technologies and to use forest wood first in wood, paper, and board industries (Report 2011). The abovementioned solutions call for energy wood to be utilised at first locally, within so-called dispersed (decentralized) energy generation in highly effective cogeneration (combined heat and power) installations. In such installations, all types of used biomass, including that of forest origin, are covered by support mechanisms (National Renewable... 2010).

Estimations made by Ratajczak et al. (2011) show, that in 2015 a demand for wood biomass in Poland may reach over 18 million $\mathrm{m}^{3}$ (i.e. 12.7 million $\mathrm{t}$ ). It means the increase by $30 \%$ as compared to 2010 . According to the authors, the future needs for wood biomass from a side of energy producer may become met, because in general the potential volume of available wood biomass seems to be large. However, not all of its sources are entirely exploited, and significant biomass reserves, being utilized to relatively small degree so far, may be found in public utilities (recovered wood) and in agriculture (energy wood plantations).

As regards wood originating from forest management, the "National Renewable Energy Action Plan" assumes that due to designation of Natura 2000 areas the overall volume of harvested timber is going to decrease. Compared to 2009, the decrease has been assumed to amount to 2.5 million $\mathrm{m}^{3}$ in 2015 and 2.74 million $\mathrm{m}^{3}$ in 2020. Restrictions in Natura 2000 areas are supposed to affect significantly forest biomass availability and it is likely to concern all timber grades, including M2, S4, and S2AC grades, which are generated as a result of timber processing and are used as fuel wood. Since the process of forest management practices modification in Natura 2000 areas is still ongoing, definitive effects of the protective restriction on timber harvesting is difficult to determine (National Renewable... 2010). 
A resource base for energy wood (S4 and M2 grades) may be supplemented by harvest residues, in particular by stumpwood, small tree branches, litter of conifer needles, and leaves. The volume of these kinds of forest biomass has been estimated to be 2 million $\mathrm{m}^{3}$ annually. Currently, however, harvesting of such biomass would bring about severe logistic problems and would not be profitable (National Renewable...2010).

Still, it seems that predictions contained in the "National Renewable Energy Action Plan" assign too big importance to the decrease in wood production due to Natura 2000 areas assignation, and do not take into consideration ongoing trends in wood resources development in the State Forests. According to Borecki and Dawidziuk (2011) the increase is assumed to amount to about $0.5 \%$ annually in the period of 2010-2030 and will be accompanied with a rise of the average age of tree stands from 61 to 65 years. It would make possible to increase the annual harvest from 32 million $\mathrm{m}^{3}$ in 2010 to 37 million $\mathrm{m}^{3}$ in 2020 , and 42 million $\mathrm{m}^{3}$ in 2030. It is also assumed that the share of final cutting in the overall felling will rise from 51\% in 2010 to $58 \%$ in 2020 , and $63 \%$ ten years later. As a consequence, one may expect an increase of a large-sized wood grades share in the total wood harvest, which may imply the necessity to adapt wood processing technologies to the changing structure of wood felled in the State Forests, considering that at present wood industries tend to demand and are fit to process mostly middle-sized wood.

In his other publication Dawidziuk (2012) presents forest resources development from 2011 to 2061. Under that study the total available cut in the State Forests is forecasted to increase from 32.4 million $\mathrm{m}^{3}$ in 2011 to 40.7 million $\mathrm{m}^{3}$ in 2031, and to 44.6 million $\mathrm{m}^{3}$ in 2061 . As regards private forests the felling is assumed to rise from 3.9 million $\mathrm{m}^{3}$ in 2011 (which was established based on the large-scale forest inventory results) to 6.0 million $\mathrm{m}^{3}$ in 2031 and to 9.7 million $\mathrm{m}^{3}$ thirty years later. On the whole, in 2031 the harvest volume would amount to 46.7 million $\mathrm{m}^{3}$, and in $2061-54.3$ million $\mathrm{m}^{3}$. BartoszewiczBurczy and Soliński (2013) assess that the potential of biomass for energy, directly originating from forests, will amount to 6.95 million $\mathrm{t}$ in 2030 and 9.47 million $\mathrm{t}$ in 2080 , which means an increase of $52 \%$ and $108 \%$ as compared to 2010 level (4.56 million $\mathrm{t}$ ), respectively.

The presented above results of different studies concerning development of forest resources in Poland indicate, that in the coming decades one may expect the rise of wood supply, including energy wood. Moreover, according to Bartoszewicz-Burczy and Soliński (2013) taking into account the limited harvest of domestic wood resources, it will be necessary to increase wood import to meet the future needs of the energy production sector for forest biomass.

It is assumed that indirectly forest wood biomass for energy would be also supplied as recovered industrial wood. At present, this kind of wood biomass is not recorded in Poland, which makes it difficult to estimate the availability of this sort of biomass for energy production. According to the Wood Technology Institute (ITD), the technical potential for recovered wood from wood industry and from other sources may be estimated to around 58.1 PJ. It is assumed, that wood processing mills generate 7.5 million $\mathrm{m}^{3}$ of waste wood annually, which accounts for $27 \%$ of the total timber felling in Poland. Because considerable part of the waste wood is utilized by the wood industry itself, some $2.5-3$ million $\mathrm{m}^{3}$ of waste wood is left for energy purposes (National Renewable... 2010).

Bartoszewicz-Burczy and Soliński (2013) assume that a volume of energy biomass from wood industries will be similar to that directly derived from forests. They estimate that in 2030 it will amount to 6,80 million $\mathrm{t}$ and in $2080-9.25$ million $\mathrm{t}$, while in 2010 it was some 5.50 million $\mathrm{t}$.

\section{Potential impact of energy wood HARVESTING ON WOOD INDUSTRIES}

The use of forest biomass for energy generation has beneficial effects on carbon balance and climate change mitigation, and also creates a possibility to utilize local forest resources and to develop dispersed energy generation. It allows to create new jobs and to economically activate non-industrialized regions (BartoszewiczBurczy and Soliński 2013).

At the same time rapid development of wood-based energy generation implies considerable threats. Some studies indicate, that in the coming years supply of wood in Europe may be insufficient to satisfy both energy generation and wood industry needs. It is likely that even substantial mobilization of wood resources and improvement in waste wood recovering will not be sufficient 
enough to avoid wood deficiency and will not protect from the necessity to import it. Based on the EFSOS report, the annual shortage of wood in Europe is assumed to be from 9 to 188 million $\mathrm{m}^{3}$ depending on the scenario. The deficit of wood would not occur only in the described above Reference scenario (UNECE 2011). Some studies indicate however that already in 2020 the shortage of wood may amount to even 230 to 500 million $\mathrm{m}^{3}$, which equals to as much as one third of the total demand for wood in that time (Bernasiński 2011).

The rising share of renewable energy in the total energy consumption already now causes an increased demand for wood. Thus, the energy sector becomes a substantial competitor for wood industries as regards wood resources. It affects mostly board industry, based on middle- and small-sized wood (Ratajczak 2011).

The raw material availability at a competitive price is a critical factor for their market competitiveness as woody raw material comprises a substantial part of the total variable production costs: more than $30 \%$ of the total costs in paper making and reaching up to 65 to $70 \%$ in the sawmill industry (Communication 2008). As far as development of wood-based energy production may be even beneficial for sawmill industry, because it causes a rise of prices for wood secondary products (slabs, chips, sawdust), the wood-based panel industries are likely to be negatively affected due to increasing competition for slabs, chips and sawdust from the sawmills as well as for roundwood (Elobio 2010).

In view of diminishing availability of sawmill by-products which are being used for energy pellets, board industry gradually turns to the use of recovered wood. Situations differ from one country to the other and regionally, but in countries like Belgium, Denmark, France, Germany, Italy and the Iberian Peninsula, where already $20 \%$ or more of the raw material for particleboard consists of recovered wood, the trend is evident. Extra costs for collecting, analysing and cleaning of recovered wood are additionally covered by the board industry plants (EFP 2005).

The problem is noticed and pointed out by the European Panel Federation (EPF), representing the European manufacturers of particleboard, MDF and OSB. Several years ago the EPF called the European Commission to revise its energy policy principles regarding use of wood for energy production and to adopt solutions ensuring development of forest-based industries, in order to maintain jobs and create socially and environmentally sustainable grounds for prevention against climate change. At present, as a consequence of a competition between financially supported renewable energy production and wood industry, the danger of a decrease in production possibilities of the latter in the European Union is emerged (Bernasiński 2011).

The Federation argues that use of wood for energy generating, apart from its negative market effects for board industry and their profitability, also has negative influence on $\mathrm{CO}_{2}$ emissions, because forest biomass combustion impairs a positive effect of carbon sequestration in final wood products. Wood combustion for energy purposes should take place only at the end of the wood value-chain. Simple use of wood for energy production shortens significantly a cycle of carbon sequestration in final products (EPF 2005). A similar point of view is presented by Bartoszewicz-Burczy and Soliński (2013). The authors stress, that forest biomass supplies for energy generation should not impede wood supplies for high profitable paper and wood industries, which secure jobs and livelihood for many people in underdeveloped regions.

The demand for biomass in the energy sector, will depend on three essential factors: the fossil fuel prices, energy and climate change policy measures applied (i.e. taxes, subsidies, etc.), and the development of other renewable energy technologies on the market (Elobio 2010). The EU subsidies and support schemes made energy production sector more competitive in terms of wood purchasing compared to other wood industries, which are granted no financial support for their activities. As an example, the subsidies in Great Britain enable the power industry to pay as much as $92 € / t$ of wood (Bernasiński 2011). Yet, in Austria from 2001 to 2005 sawdust prices nearly doubled because of the increased competition between pellet producers and the pulp and panel industries for the same raw material. Pellets have also experienced significant rise in price, reaching up to $265 € / t$ from average prices of $183 € /$ t, mainly due to high demand from heating sector combined with the shortage of round wood (Elobio 2010).

The use of biomass for energy production has influenced improvement of agriculture and is assumed to further benefit it and thus it should be an essential issue of the agricultural policy (National Renewable... 2010). However, the wide use of forest biomass may be harm- 
ful for development of rural areas, because it may weaken some branches of wood industry, which contribute substantially to economic development (Bernasiński 2011). It is assumed that wood-based manufacturing in the EU generated 114.1 billion $€$ of value added from 413.2 billion $€$ of turnover in 2008 , and it employed almost 2.8 million persons, i.e. $8.4 \%$ of manufacturing employment (Eurostat 2011).

Use of wood by wood processing industry is economically more efficient than use of wood for energy production. It is estimated, that even without taking into account the energy content of wood-based materials at the end of their lifecycle, the added value of wood products was calculated to be 1044 EUR/t of dry wood, as compared to $118 \mathrm{EUR} /$ to for fuel use. Moreover, woodbased products, on average, generate 54 man-hours/t of dry wood, whereas energy use generates only 2 manhours/t (EFP 2005).

Unfavourable conditions for wood-based panel industry in Europe may result in shifting production to "cheaper" regions and countries. For several years this industry is considering alternative scenarios like delocalisation to countries from outside the EU (like Ukraine and Russia, but also to China). Such scenarios would not only be detrimental to employment in the EU's wood-based panel industry, but also to downstream activities like furniture manufacturing, a sector already endangered by growing imports of cheap goods from outside Europe (EFP 2005).

\section{Conclusions}

The question of utilization of forest biomass for largescale energy generation is very complex and has farreaching consequences for environment, society and economy. Because of its scale it gives also new insight into the importance of wood, and therefore it defines a new role for forest management as a sector supporting fulfilment of climate policy goals. Active implementation of climate policy objectives implies searching for ways of sustainable wood resources mobilization. It also requires that all benefits and costs are taken into consideration, so as fulfilment of climate policy goals would not conflict the development of other ways of using wood and would not threaten for wood-based industries. Effective wood resources management should give a priority to wood-based production of the greatest added value. It would allow to create new jobs and contribute to betterment of carbon balance in the first place. From this point of view energy generation should be a closing-down stage in the wood value chain.

\section{AcknOWLedgements}

The paper presents the results of the research implemented within the project "Possibilities and natural, technological and economic conditions of increasing supply of wood for energy production" financed by the Polish National Science Centre (grant number N N309 110940).

\section{References}

Ballaun A. 2013. Actual possibilities of harvest and the offer for sale of fuel wood in the State Forests. In: Forest biomass for energy purposes (in Polish) (eds.: P. Gołos, A. Kaliszewski), Forest Research Institute, Sękocin Stary, 197-201.

Bartoszewicz-Burczy H., Soliński J. 2013. Use of forest biomass for energy production - current state and prospects until 2030 and 2080 (economic, organizational, and technological conditions, support instruments). Paper presented during the $1^{\text {st }}$ Expert Panel of the National Forest Programme, 16 June 2013, Sękocin Stary, Poland (in Polish). http://npl. ibles.pl/klimat. Accessed 10 January 2014.

Bernasiński R. 2011. Energy production - is it worth wasting wood for energy production? (in Polish). http://www.plytameblowa.pl. Accessed 12 March 2012.

Borecki T., Dawidziuk J. 2011. Assessment of the development, productivity, structure, and destination of forest resources. In: Development strategy for forests and forestry in Poland until 2030. Winter Forestry School at the Forest Research Institute. 3rd Session. Sękocin Stary, 15-17 March 2011 (in Polish). Forest Research Institute, Sękocin Stary, Poland, 121-136.

Communication from the Commission to the Council and the European Parliament on innovative and sustainable forest-based industries in the EUA contribution to the EU's Growth and Jobs Strategy. $\operatorname{COM}(2008) 113$ final, \{SEC(2008) 262\}. 
Communication from the Commission to the European Parliament, the Council, the European Economic and Social Committee and the Committee of the Regions. Analysis of options to move beyond 20\% greenhouse gas emission reductions and assessing the risk of carbon leakage. $\operatorname{COM(2010)~} 265$ final, [SEC(2010) 650].

Dawidziuk J. 2012. Current state and projections for development and utilization of forest resources in Poland. In: Natural and economic aspects of wood production and utilization: current state and projections. Winter Forestry School at the Forest Research Institute. 4th Session. Sękocin Stary, 20-22 March 2012 (in Polish). Forest Research Institute, Sękocin Stary, Poland, 104-117.

Directive 2009/28/EC of the European Parliament and of the Council of 23 April 2009 on the promotion of the use of energy from renewable sources and amending and subsequently repealing Directives 2001/77/EC and 2003/30/EC. OJ L 140, 05.06.2009.

Elobio. 2010. Biofuel policies for dynamic markets. Elobio Policy Paper 5. April 2010 "Lignocellulosic markets special". Elobio - Effective and low-disturbing biofuel policies. Energy Research Centre of the Netherlands, Petten.

Energy Policy of Poland until 2030. Document adopted by the Council of Ministers on 10 November 2009. Ministry of Economy, Warsaw, Poland.

EPF. 2005. Sustainable use of wood for products and energy: conflict or opportunity? (View of the European wood-based panel industry). European Panel Federation, Brussels. http://www.europanels.org/ main_tc.html. Accessed 20 August 2012.

Eurostat. 2011. Forestry in the EU and the world. A statistical portrait. 2011 edition. Publications Office of the European Union, Luxembourg.

Government Legislation Centre. 2014. Draft law on renewable energy sources. http://legislacja.rcl.gov.pl. Accessed 6 January 2014.

GUS. 2011. Forestry 2011. Central Statistical Office, Warsaw, Poland.

Mantau U. 2010. Is there enough wood for Europe? In: Mantau U. et al. EUwood: Real potential for changes in growth and use of EU forests. Final report. Hamburg, Germany, June 2010. 19-34.
National Renewable Energy Action Plan. Poland. Document adopted by the Council of Ministers on 7 December 2010 Minister of Economy, Warsaw, Poland.

Ratajczak E. 2011. Demand for wood in Poland - structural changes and supply possibilities. In: Development strategy for forests and forestry in Poland until 2030. Winter Forestry School at the Forest Research Institute. 3rd Session. Sękocin Stary, 15-17 March 2011 (in Polish). Forest Research Institute, Sękocin Stary, Poland, 151-166.

Ratajczak E., Bidzińska G., Szostak A., Herbeć M. 2011. The polish wood-based sector in the European Union - possibilities to compete and development prospects against a background of a projected situation on the timber market (in Polish). Wood Technology Institute, Poznań, typescript.

Regulation of the Minister of Economy of 14 August 2008 on a detailed scope of the obligations in respect to obtaining certificates of origin and submitting them for cancellation, payment of a substitution fee, purchase of electricity and heat from renewable energy sources, as well as the obligation to confirm the data on the amount of electricity produced from a renewable energy source. Journal of Laws No 156, item 969, as amended. In Polish.

Regulation of the Minister of Economy of 23 February 2010 amending the Regulation on a detailed scope of the obligations in respect to obtaining certificates of origin and submitting them for cancellation, payment of a substitution fee, purchase of electricity and heat from renewable energy sources, as well as the obligation to confirm the data on the amount of electricity produced from a renewable energy source. Journal of Laws No 34, item. 182. In Polish.

Report: Analysis of the fulfilment of quantitative and qualitative objectives, as well as results gained regarding electricity production with the use of renewable energy sources in 2009-2010, 2011. Document adopted by the Committee on the European Affairs on 9 September 2011 (in Polish). Minister of Economy, Warsaw, Poland.

UNECE. 2011. The European Forest Sector Outlook Study II. 2010-2030. United Nations Economic Commission for Europe, Geneva, Switzerland. 